\title{
Effect of Nanoalumina on the Electrochemical and Mechanical Properties of Waterborne Polyurethane Composite Coatings
}

\author{
Shailesh K. Dhoke, Narayani Rajgopalan, and A. S. Khanna \\ Department of Metallurgical Engineering and Materials Science, Indian Institute of Technology Bombay, Powai, Mumbai 400076, India \\ Correspondence should be addressed to Shailesh K. Dhoke; shailesh_zeo@rediffmail.com
}

Received 27 November 2012; Revised 23 April 2013; Accepted 23 April 2013

Academic Editor: Vijaya Rangari

Copyright ( 2013 Shailesh K. Dhoke et al. This is an open access article distributed under the Creative Commons Attribution License, which permits unrestricted use, distribution, and reproduction in any medium, provided the original work is properly cited.

\begin{abstract}
A nanocomposite coating was formed by incorporating nanoalumina pigment in a waterborne polyurethane dispersion (WPUD) to different loading levels $(0.1 \%$ and $1.0 \%$ by weight $)$. Electrochemical performance of the nanocomposite coating was evaluated by applying these nanomodified coatings on mild steel substrate and exposing them to salt-spray, humidity, and accelerated UV weathering. The surface morphology of the composite coating was evaluated using various analytical techniques. SEM and AFM were used to investigate the dispersion of nanoalumina pigment and surface morphological changes of the nanomodified coating, before and after exposure to the test environment. Mechanical properties like scratch resistance were studied by using nanoscratch technique (Nanoindenter TI-900, Hysitron Inc, USA) and hardness using pencil hardness test method. The results showed an improvement in the corrosion, UV weathering, and mechanical properties of the coatings at lower concentration $(0.1 \%$ by wt), indicating the positive effect of addition of nanoalumina pigment to the coating.
\end{abstract}

\section{Introduction}

An aqueous polyurethane dispersion is a binary colloid system in which polyurethane particles are dispersed in a continuous aqueous medium $[1,2]$. The basic building blocks of solvent borne polyurethanes like diisocyanates, polyols, amines catalysts, and additives are common to aqueous-based system as well [3]. Though, the development of aqueous polyurethane dispersions was motivated primarily by environmental considerations, one technical advantage of aqueous polyurethane dispersion is that the viscosity of dispersion is independent of the molecular weight of polymer. Thus, polyurethane dispersion can be prepared at a high solid content with a molecular weight high enough to form films with excellent performance solely by physical drying [2]. Economical aspect is another reason as they do not contain the expensive solvents [3]. Compared to their solvent counterparts, polyurethane dispersions can offer the following advantages: viscosity and flow properties independent of molecular weight, the absence of external emulsifiers, environmental safety, good adhesion, and rheology characteristics [4]. Other advantages which make them attractive as waterborne coatings are the outstanding properties of solvent, stain, chemical resistance, and toughness with flexibility [5].

Also, it has been found that additive and pigments not only provides esthetics to the waterborne coatings, but also helps in improving many properties of the coatings such as UV resistance, corrosion resistance. With the quest for new developed coating systems with better performance, aqueous-based polyurethane coatings are modified with various nanoparticles [6-13]. Nanotechnology presents a wide range of opportunities to improve performance of coatings and promises to deliver breakthrough performance specifically with respect to scratch and mar resistance, barrier properties including corrosion resistance and mechanical properties $[14,15]$. Optical clarity is one of the many features of nanoparticles, extremely important in expanding nanoparticle applications in coatings. They can be added to a clear coating formulation with little or no adverse impact on visual characteristics. Nanoparticles most commonly used in coatings are $\mathrm{SiO}_{2}[7,11-13], \mathrm{TiO}_{2}[16], \mathrm{ZnO}[6,8,9,17]$, $\mathrm{Al}_{2} \mathrm{O}_{3}$ [18-21], $\mathrm{Fe}_{2} \mathrm{O}_{3}$ [22], and $\mathrm{CaCO}_{3}$ [23], $\mathrm{ZrO}_{2}$ [24]. Use of nanoparticles is most commonly based on the inherent 
properties they possess. For example, nanotitania and nanozinc oxide are most commonly used as UV blocking agents, whereas nanoalumina and nanosilica are used to improve scratch and abrasion resistance of the coating. The enhanced properties are result of the much greater surface to volume ratio of the nanopigment that is often characterized by very high aspect ratios [25].

Present study refers to the effect of addition of nanoalumina on water-borne polyurethane coating system at two different loading levels ( $0.1 \%$ and $1.0 \%$ by weight). Alumina is a harder material (hardness on Mohs's scale is 9) and is mostly used to modify coatings in order to improve its scratch and abrasion resistance. The nanomodified coatings were applied on pretreated mild steel panels by dip coating techniques. Dip coating techniques can be described as a process where the substrate to be coated is immersed in a liquid and then withdrawn with a well-defined withdrawal speed under controlled temperature and atmospheric conditions. The coating thickness is mainly defined by the withdrawal speed, by the solid content, and by the viscosity of the liquid. Dip coating was used keeping into view the industrial viability of the coating. Using this technique, uniform film can be applied onto flat and cylindrical substrates with ease and high production rates and high transfer efficiency. The process is cost effective and requires low labor as compared to other application process. The performance behavior of the nanoparticle modified coating systems with respect to electrochemical, UV resistance, and mechanical properties was investigated.

\section{Experimental}

2.1. Material Used. Nanoalumina (Nano DurTM), of nanoparticle size ranges from $30-47 \mathrm{~nm}$ with a mean size of $35 \mathrm{~nm}$ and specific area of $35 \mathrm{~m}^{2} \mathrm{~g}^{-1}$, was procured from Johnson Mathey Company. A one-pack translucent waterborne polyurethane dispersion (WPUD) based on aliphatic urethane with approximately $34 \%$ of total solid content was procured from Dooall Corporation Pvt. Ltd, India.

\subsection{Preparation of Nanoparticle Modified Polyurethane} Waterborne Coating. Waterborne polyurethane dispersion (WPUD) was stabilized with nanoalumina pigments in different concentrations by ultrasonic probe dispersion equipment $(100 \mathrm{~W}, 40 \mathrm{khz})$ for about 45 minutes until a clear coating was obtained. To minimize temperature driven side effects during sonication, the suspension container was immersed in a cooling bath. The nanomodified coating system thus formed was applied on pretreated cold roll steel panels by dip coating. Dip coating techniques can be described as a process where the substrate to be coated is immersed in a liquid and then withdrawn with a welldefined withdrawal speed under controlled temperature and atmospheric conditions. The coating thickness is mainly defined by the withdrawal speed, by the solid content, and by the viscosity of the liquid. Dip coating was used keeping into view the industrial viability of the coating. Using this technique, uniform film can be applied onto flat and

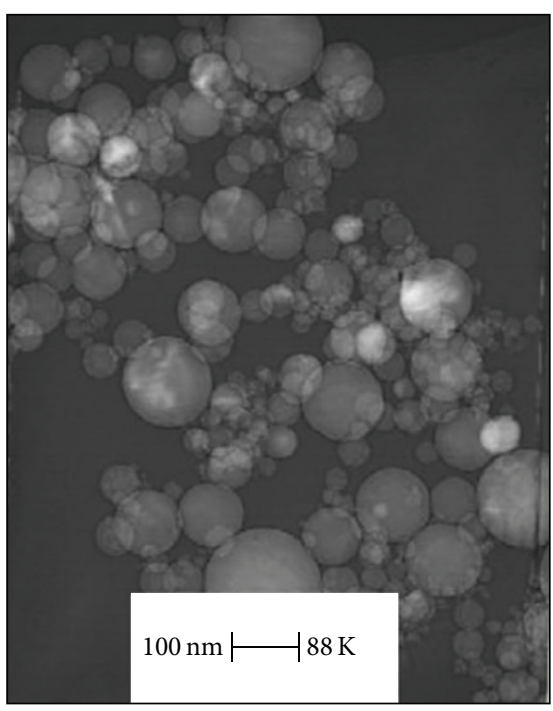

FIgURE 1: TEM photograph of nano- $\mathrm{Al}_{2} \mathrm{O}_{3}$ particles.

cylindrical substrates with ease and high production rates and high transfer efficiency. The process is cost effective and requires low labor as compared to other application process. Pretreated mild steel substrates $\left(3^{\prime \prime} \times 6^{\prime \prime}\right)$ were immersed in the solution of the coating material at a constant speed and held in coating bath for a while. The substrate was pulled up from the bath, while the thin layer of the coating deposits itself on the substrate. The excess coating dripping from the substrate was wiped off and the coating was allowed for oxidative curing at room temperature for 24 hours. The average coating thickness was found to be $10 \mu \mathrm{m}$. The coated panels were used for electrochemical and mechanical characterizations.

2.3. Characterization. The powder nanoparticles were investigated by transmission electron microscopy (TEM, Philips CM200) for its shape and size. Electrochemical behavior of the coating was studied by exposing the coated test panels to Salt Spray (ASTM B117), Humidity (ASTM D 2247), and UV weathering (ASTM D 4587) tests. Surface morphology of the coatings after electrochemical studies was determined using scanning electron microscopy (SEM, Model no. S3400, Hitachi) and atomic force microscopy (AFM, Digital Instrument Nanoscope IV). For SEM and AFM study a $1 \mathrm{~cm} \times 1 \mathrm{~cm}$ size peace was cut from the sample. Mechanical properties like scratch resistance were studied by using nanoscratch technique (Nanoindenter TI-900, Hysitron Inc, USA) and hardness using pencil hardness test method (ASTM D-336305(2011)e2).

\section{Results and Discussion}

3.1. Characterization of Nanoalumina Oxide Powders. Figure 1 shows the TEM photograph of nano- $\mathrm{Al}_{2} \mathrm{O}_{3}$ particles. It shows that the particles are of spherical shape. 


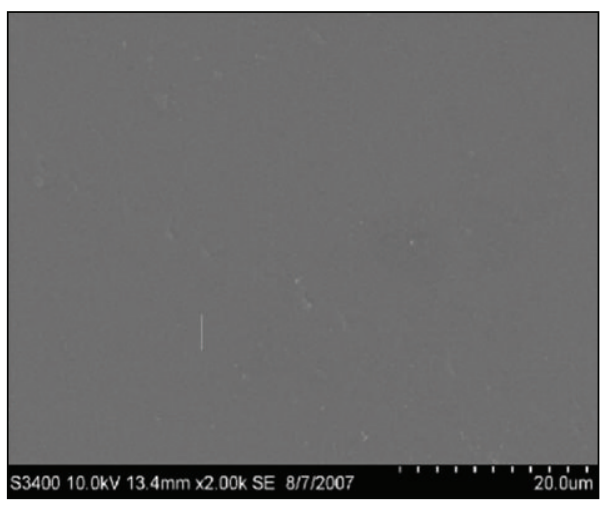

(a)

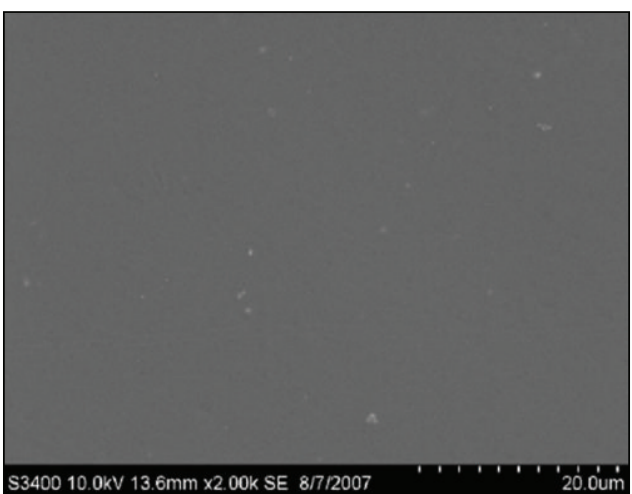

(b)

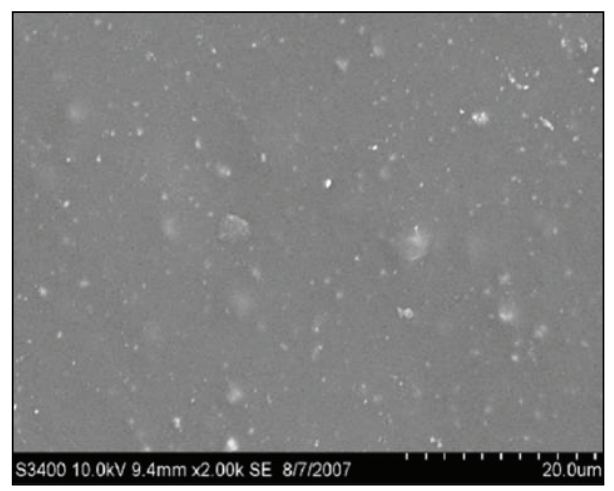

(c)

FIgURE 2: SEM micrographs of unexposed samples: (a) neat WPUD, (b) WPUD $+0.1 \%$ nano- $\mathrm{Al}_{2} \mathrm{O}_{3}$, and (c) WPUD $+1.0 \%$ nano- $\mathrm{Al}_{2} \mathrm{O}_{3}$.

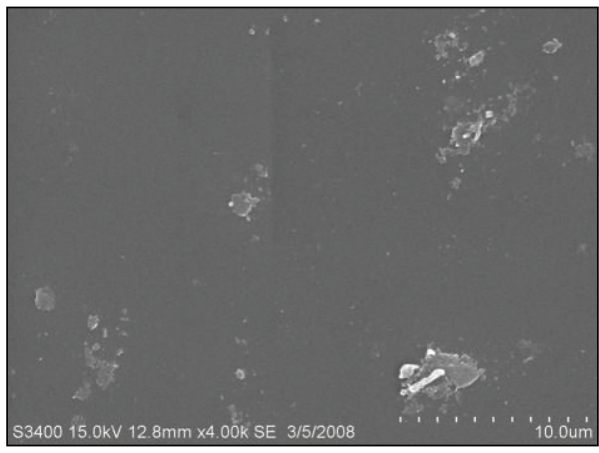

(a)

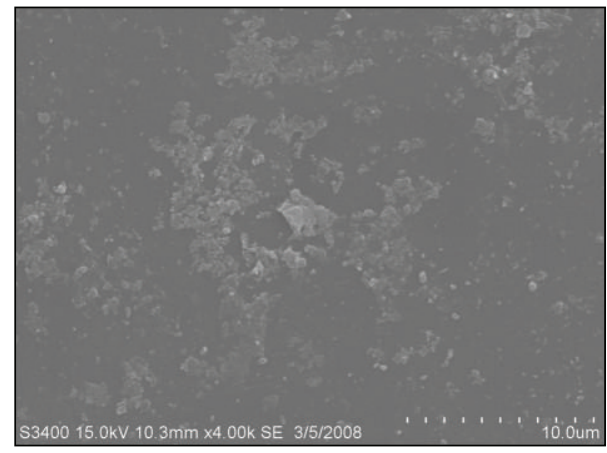

(b)

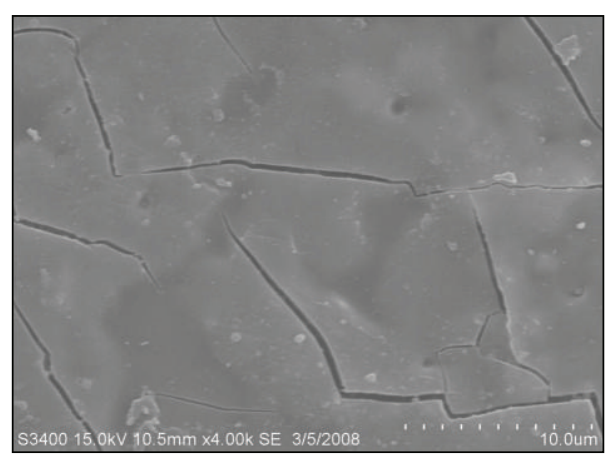

(c)

FIGURE 3: SEM micrographs of salt-spray-exposed samples: (a) neat WPUD, (b) WPUD + 0.1\% nanoalumina, and (c) WPUD + 1.0\% nanoalumina. 


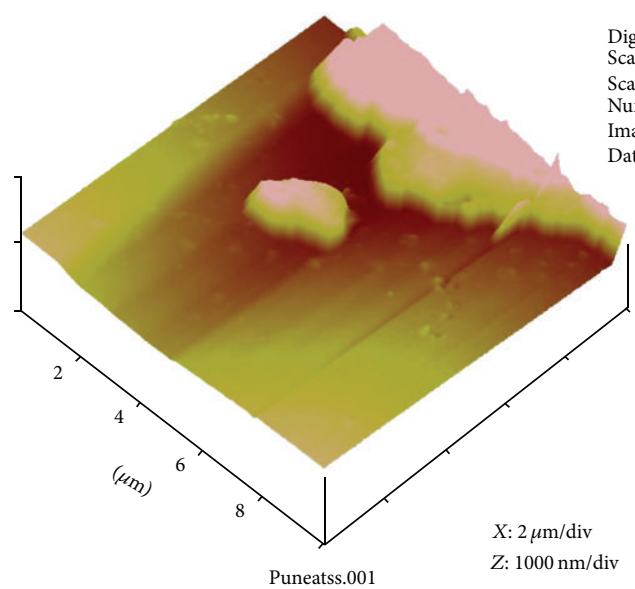

Digital instruments nanoscope nize: $10 \mu \mathrm{m}$

can rate: $1.001 \mathrm{~Hz}$

mage data: heigh

Data scale: $1 \mu \mathrm{m}$

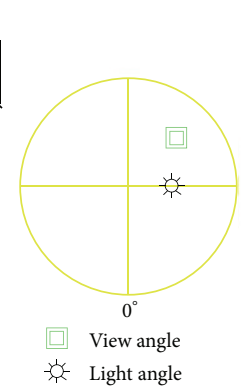

(a)

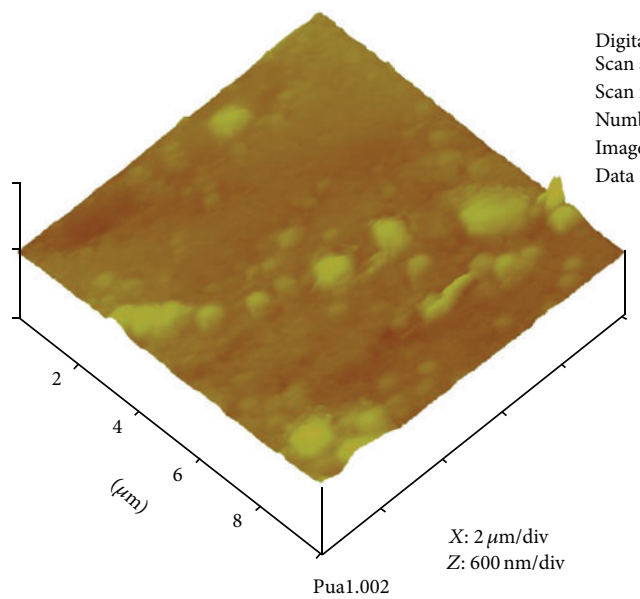

Digital instruments nanoscope Scan size: $10 \mu \mathrm{m}$

Scan rate: $1.001 \mathrm{~Hz}$

Number of samples: 25

Image data: height

Data scale: $600 \mathrm{~nm}$

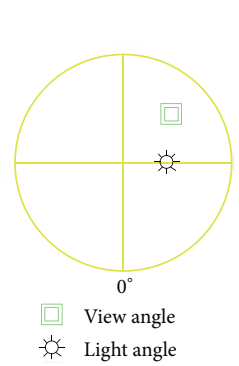

(b)

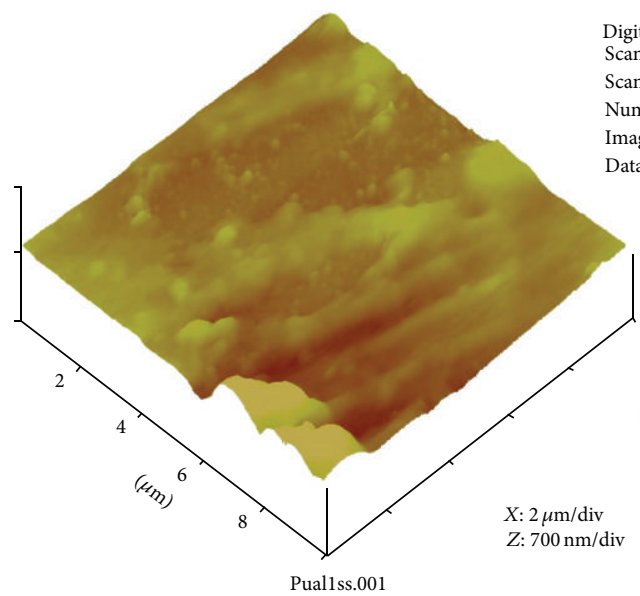

Digital instruments nanoscope nize: $10 \mu \mathrm{m}$

can rate: $1.001 \mathrm{~Hz}$

Number of samples: 256

Image data: height

Data scale: $700 \mathrm{~nm}$

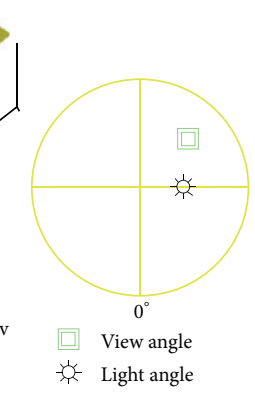

(c)
Height Angle Surface normal Clear calculator

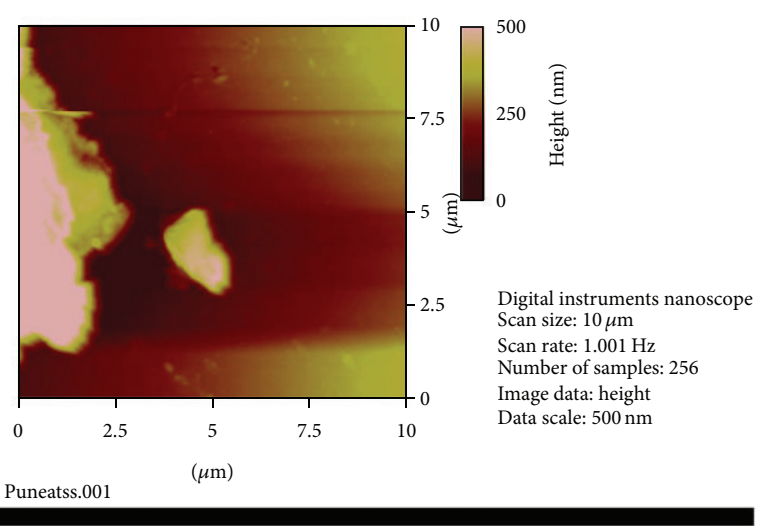

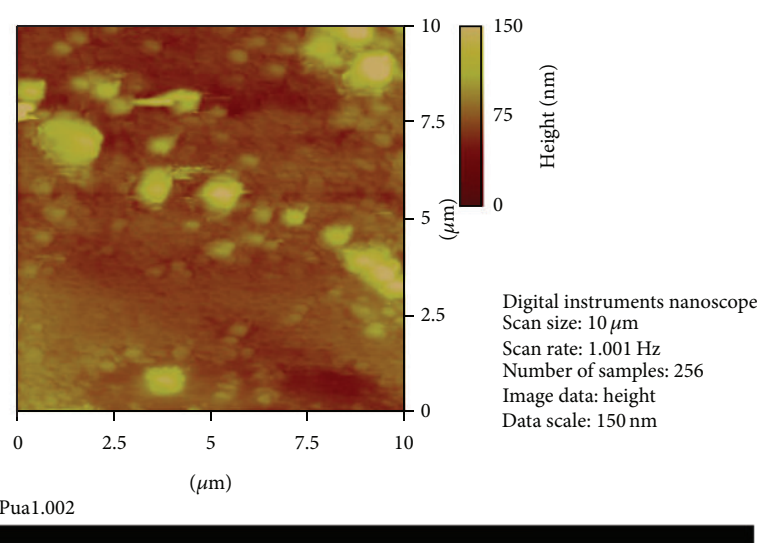
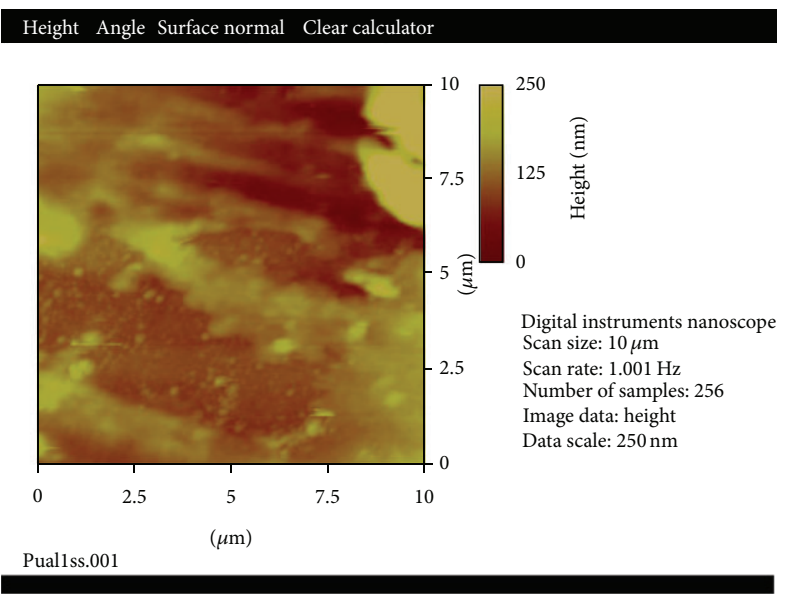

FIGURE 4: AFM topographic height images of salt-spray-exposed coating surface at a scan size of $10 \mu \mathrm{m} \times 10 \mu \mathrm{m}$ : (a) neat WPUD, (b) WPUD $+0.1 \%$ nanoalumina, and (c) WPUD + $1.0 \%$ nanoalumina. 


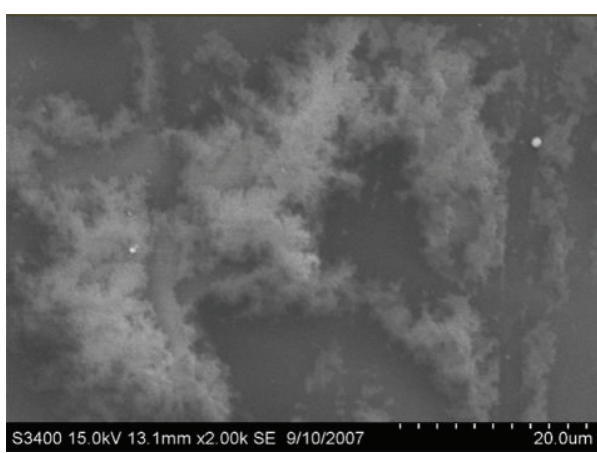

(a)

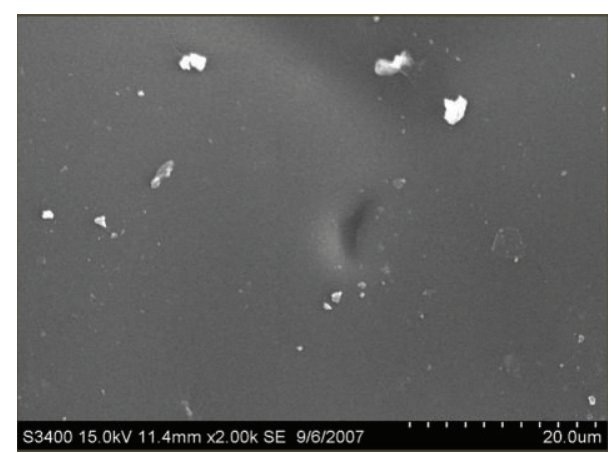

(b)

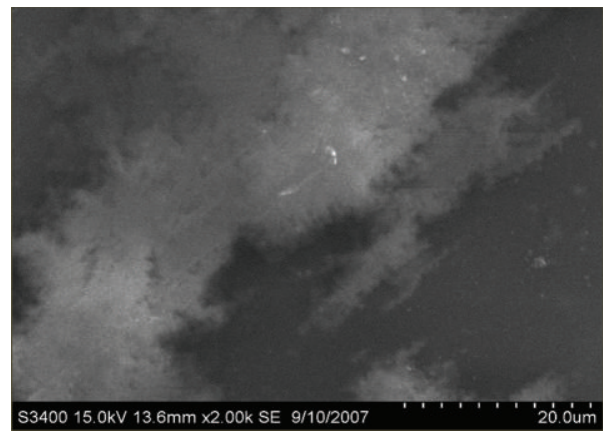

(c)

FIGURE 5: SEM micrographs of humidity-exposed samples: (a) neat WPUD, (b) WPUD + 0.1\% nanoalumina, and (c) WPUD + 1.0\% nanoalumina.

The nanoparticle size ranges from 30 to $47 \mathrm{~nm}$ with a mean size of $35 \mathrm{~nm}$.

\subsection{Characterization of Nanocomposite Coating}

3.2.1. Electrochemical Analysis by Using SEM and AFM. Surface properties of the coating before and after modification are discussed on the basis of the change of surface topography using SEM and AFM. Figure 2 shows the SEM micrographs of neat WPUD coating and coating modified with nano- $\mathrm{Al}_{2} \mathrm{O}_{3}$ particles in different loading levels, before exposure to the test environments. From Figure 2(a), it can be clearly seen that the coating formed is uniform and free from heterogeneity on the surface. After modifying WPUD with nano- $\mathrm{Al}_{2} \mathrm{O}_{3}$ particles, the coating modified with $0.1 \%$ nano- $\mathrm{Al}_{2} \mathrm{O}_{3}$ particles (Figure $2(\mathrm{~b})$ ) shows uniform surface morphology indicating proper dispersion of nanoparticles, while the surface micrograph of coating modified with $1.0 \%$ nano- $\mathrm{Al}_{2} \mathrm{O}_{3}$ particles (Figure $2(\mathrm{c})$ ) shows white spots all over the surface indicating agglomeration of the nanoparticles.

Salt-Spray Exposure. Figure 3 shows the surface micrographs of the neat WPUD and nanocomposite coatings after 800 hours of exposure in salt spray chamber. From Figure 3, it can be seen that the coating degradation after exposure to salt spray is more distinct on neat sample (Figure 3(a)) and on coating modified with $1.0 \%$ nanoalumina (Figure $3(\mathrm{c})$ ) where appearance of microcracks is observed. However, the performance was as comparatively better for the coating modified with $0.1 \%$ nanoalumina (Figure $3(\mathrm{~b})$ ). The degradation of neat WPUD coating resulting into chemical changes during exposure is attributed to the fact that coating without barrier pigments is permeable to water and other corrosion initiators such as chloride and oxygen. However, after modification of WPUD with nanoalumina, it is suggested that the concentration of nanoparticles has dramatic effect on corrosion protection properties of these nanocomposites. At lower loading level ( $0.1 \%$ nanoalumina), the concentration of nanoalumina particle is so small that the well-disperse particles in the coating restrict the diffusion of the corrosive electrolyte through the coating film acting as an effective barrier. It may be attributed that for lower loading level of nanoalumina, the well-dispersed particle having large surface area and small size absorbs more resin on its surface which enhances the density of the coatings thereby reducing the transport paths for the corrosive electrolyte to pass through the coating and consequently reducing the corrosion process $[9,26,27]$. At higher loading level $(1.0 \%$ nanoalumina), the increase in the number of particles in the coating surpasses the critical loading level which may lead to agglomeration of the particles resulting in microsize defects at the agglomerated site. These agglomerates because of their high surface activity introducing defect like crack and increasing brittleness in nanocomposite coatings. These defects act as site for electrochemical reaction affecting the coating performance. AFM topographic images for saltspray-exposed samples for 800 hours also provide the same information (Figure 4). As can be seen from Figure 4(a), 


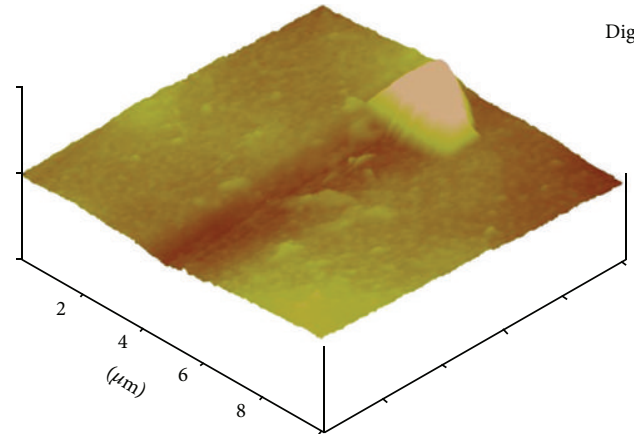

$$
\begin{gathered}
\text { 5-10-07 } \\
\text { Puneat.002 }
\end{gathered}
$$

$X: 2 \mu \mathrm{m} / \mathrm{div}$

$Z: 2000 \mathrm{~nm} / \mathrm{div}$
Digital instruments nanoscope Scan size: $10 \mu \mathrm{m}$ Scan rate: $1.507 \mathrm{~Hz}$ Number of samples: 256 Image data: height Data scale: $2 \mu \mathrm{m}$

प View angle 凉- Light angle

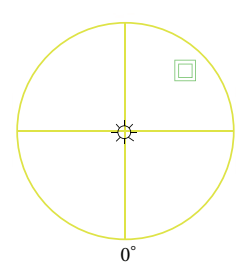

\section{Height Angle Surface normal Clear calculator}

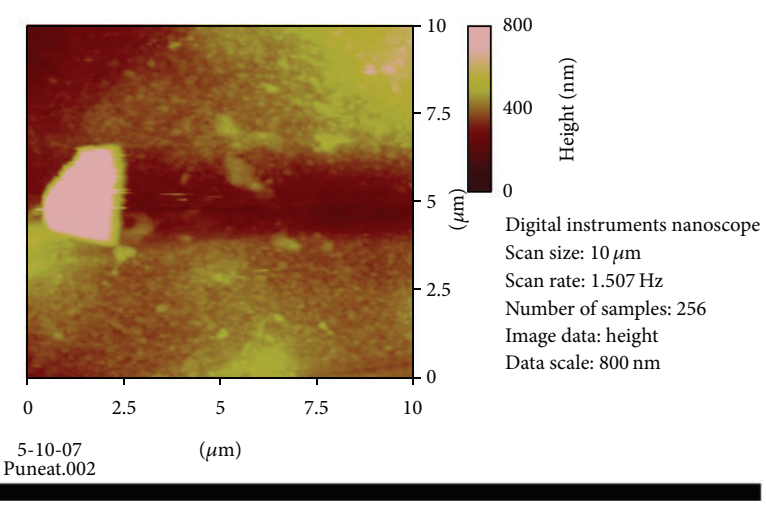

(a)

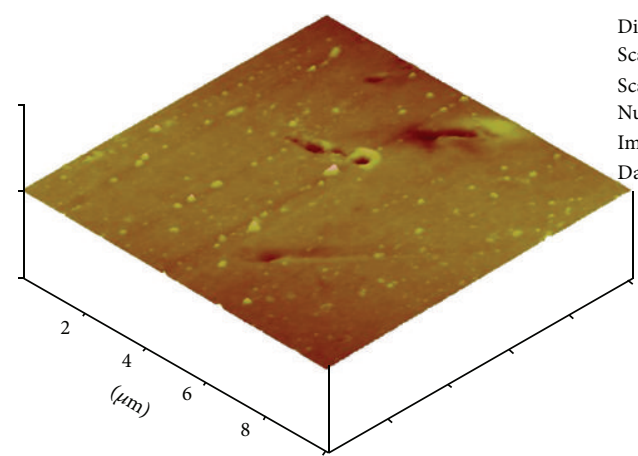

5-10-07
Pual.001

$Z: 1000 \mathrm{~nm} / \mathrm{div}$
Digital instruments nanoscope

Scan size: $10 \mu \mathrm{m}$

Scan rate: $1.507 \mathrm{~Hz}$ Number of samples: 256

Image data: height

ata scale: $1 \mu \mathrm{m}$

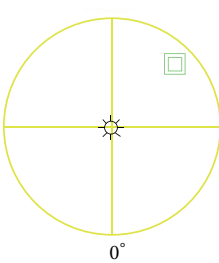

$\square$ View angle $-\not<-$ Light angle
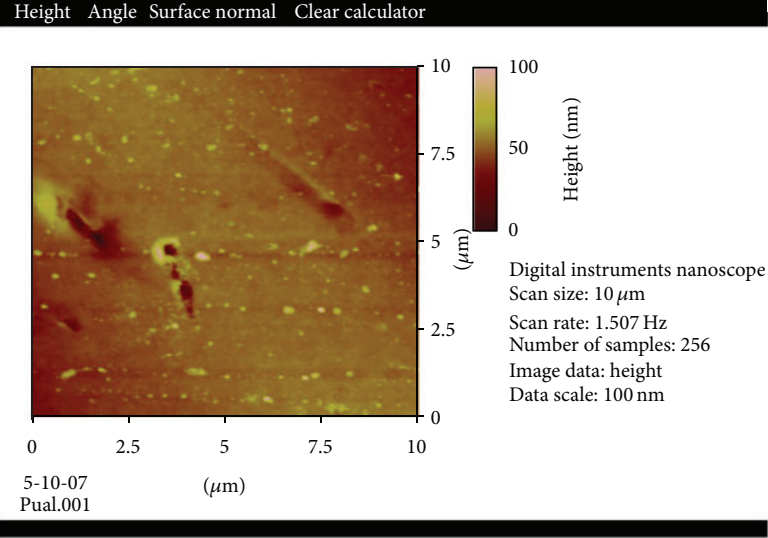

(b)

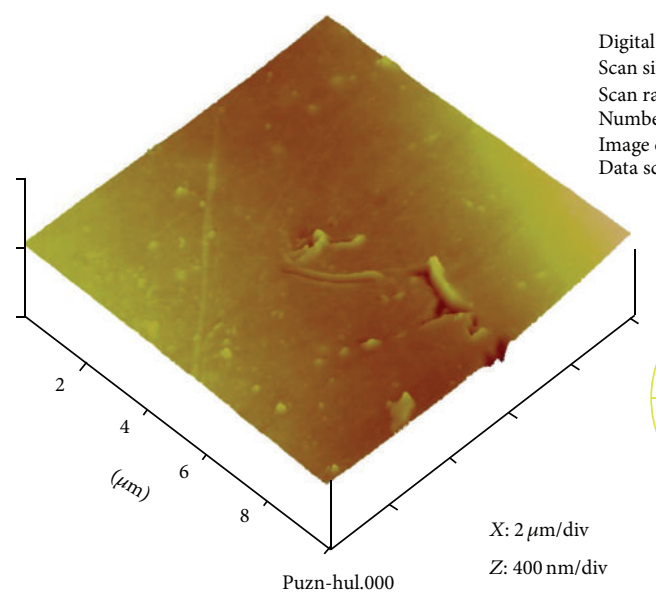

Digital instruments nanoscope Scan size: $10 \mu \mathrm{m}$ rate: $1.001 \mathrm{~Hz}$

ber of samples: 256

nage data: height scale: $400 \mathrm{~nm}$

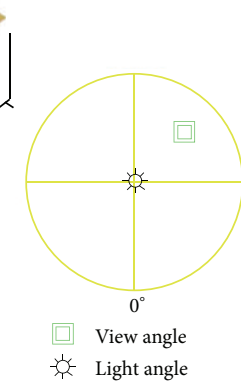

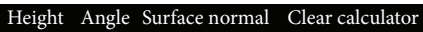

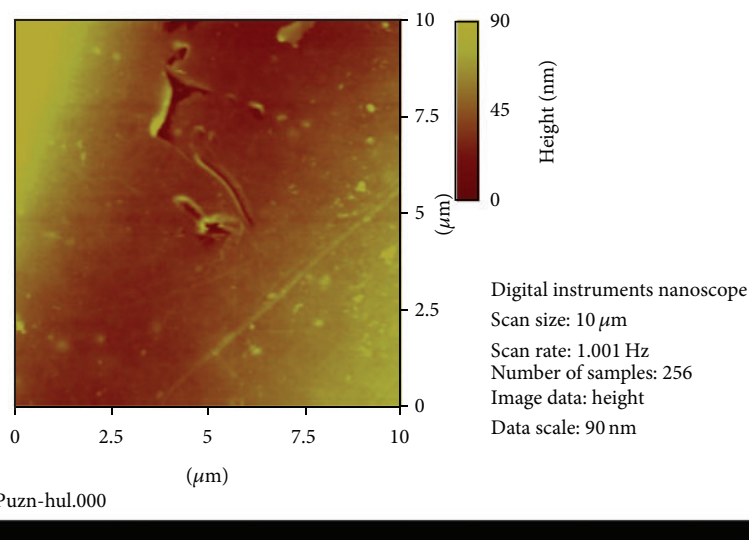

(c)

FIGURE 6: AFM topographic height images of humidity-exposed coating surface at a scan size of $10 \mu \mathrm{m} \times 10 \mu \mathrm{m}$ : (a) neat WPUD, (b) WPUD $+0.1 \%$ nanoalumina, and (c) WPUD $+1.0 \%$ nanoalumina. 


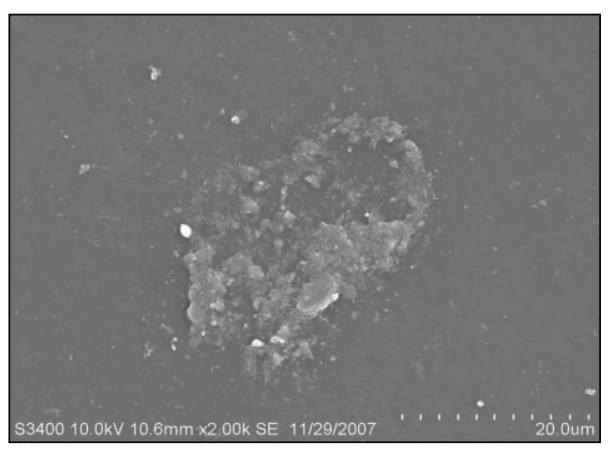

(a)

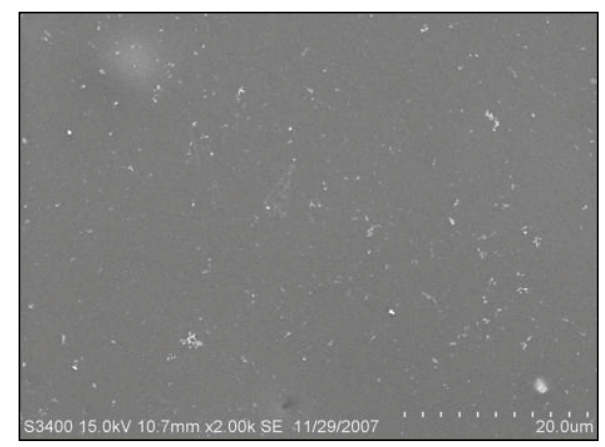

(b)

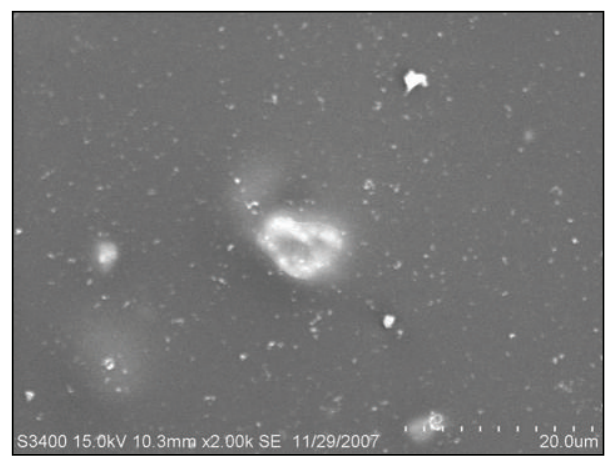

(c)

FIGURE 7: SEM micrographs of UV-exposed samples: (a) neat WPUD, (b) WPUD + $0.1 \%$ nanoalumina, and (c) WPUD + $1.0 \%$ nanoalumina.

the surface of neat sample and coating modified with $1.0 \%$ nanoalumina (Figure 4(c)) is completely heterogeneous due to breakdown of polymer matrix as compared to coating modified with $0.1 \%$ nanoalumina (Figure $4(\mathrm{~b})$ ), which shows a little change on the surface appearance, indicating better protection. It is appeared that the neat coating had undergone the breakdown of polymer matrix due to long exposure to the electrolyte, whereas the addition of critical amount of nano$\mathrm{Al}_{2} \mathrm{O}_{3}$ had retarded the diffusion of corrosive species.

Humidity Exposure. Figure 5 shows the SEM micrographs of humidity-exposed samples. From Figure 5, the effect of humidity was more pronounced on neat sample (Figure 5(a)) and on coating modified with $1.0 \%$ nanoalumina (Figure 5(c)) as compared to coating modified with $0.1 \%$ nanoalumina (Figure 5(b)). The surface micrograph of the neat sample (Figure 5(a)) shows presence of blisters all over the surface. This indicates that the coating has undergone drastic changes during exposure leading to the failure. With the incorporation of $0.1 \%$ of nanoalumina pigment in the coating system, no such defects were observed. As can be seen from the SEM micrographs (Figure 5(b)) coating at lower loading level $(0.1 \%)$ appears more uniform and devoid of areas of delamination, degradation, and blisters. This again can be attributed to proper pigment concentration and dispersion in the polymer matrix. Also, the interaction of the nanoalumina with the polymer is strong, whereby the strongly bounded interface does not allow the permeation of water [20, 21]. However, at higher loading level (Figure 5(c)), heterogeneities are clearly observed similar to that of neat coating. This can be attributed to improper pigment to polymer ratio resulting in the agglomerated site consequently leading to lose of their desired functional properties [12, 27]. AFM topographic height images (Figure 6) for humidityexposed samples also provide the parallel observations. Figure 6(a) represents AFM image of neat samples showing completely distorted surface, indicating changes in the surface roughness and microstructure of the coating. Coating system with lower concentration of nanoalumina particles $(0.1 \%$ by wt) shows little change in the surface roughness and microstructure of the coating (Figure 6(b)) as compared to the coating system (Figure 6(c)) with higher loading level (1.0\% by wt), suggesting the improvement in the humidity resistance of the coating.

UV Weathering Test. Figure 7 shows the surface micrographs of UV-exposed samples after 1000 hours, where the source of irradiation used was UV-B lamp which emits wavelength of $313 \mathrm{~nm}$. The degradation of coating due to photo-chemical interaction is distinctly observed in neatWPUD-coated sample. The presence of surface heterogeneity clearly indicates the degradation of coating due to longterm exposure to UV radiation (Figure $7(\mathrm{a})$ ). The coating modified with nanoalumina showed an improvement in the UV resistance. No changes were observed for the coating modified with $0.1 \%$ of nanoalumina (Figure $7(\mathrm{~b})$ ). However, for coating modified with $1.0 \%$ of nanoalumina (Figure $7(\mathrm{c})$ ), appearance of pin holes is clearly observed. This suggests that though the induction time for surface degradation is delayed, the performance of the coating was inferior as 


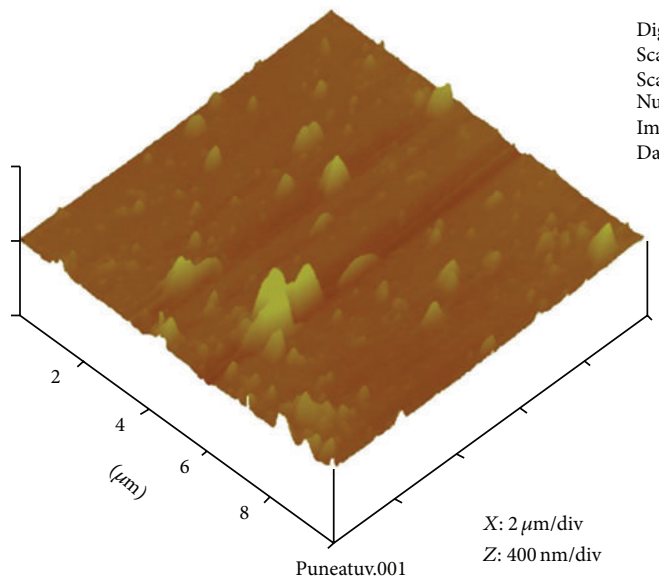

Digital instruments nanoscope Scan size: $10 \mu \mathrm{m}$

Scan rate: $1.507 \mathrm{~Hz}$

Image data: height Data scale: $400 \mathrm{~nm}$

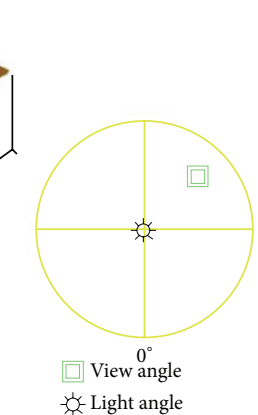

(a)

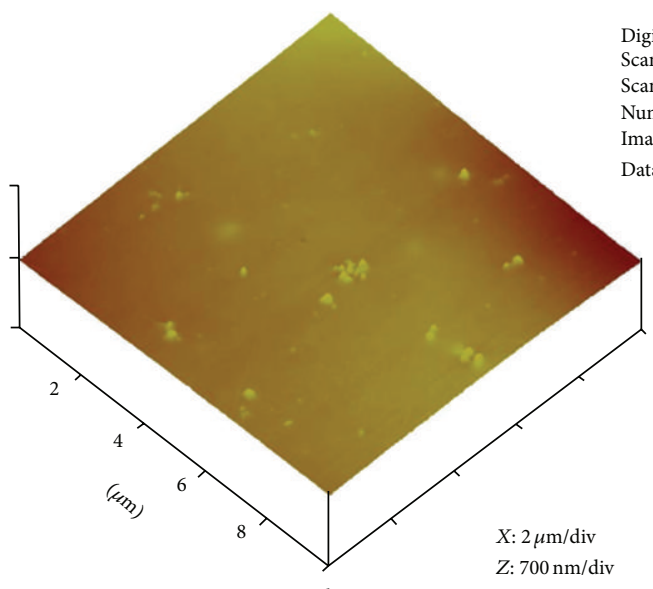

Digital instruments nanoscope Scan size: $10 \mu \mathrm{m}$

Scan rate: $1.001 \mathrm{~Hz}$

Number of samples: 256

mage data: height

ata scale: $700 \mathrm{~nm}$

Pual-0.002

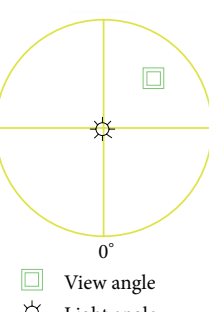

(b)

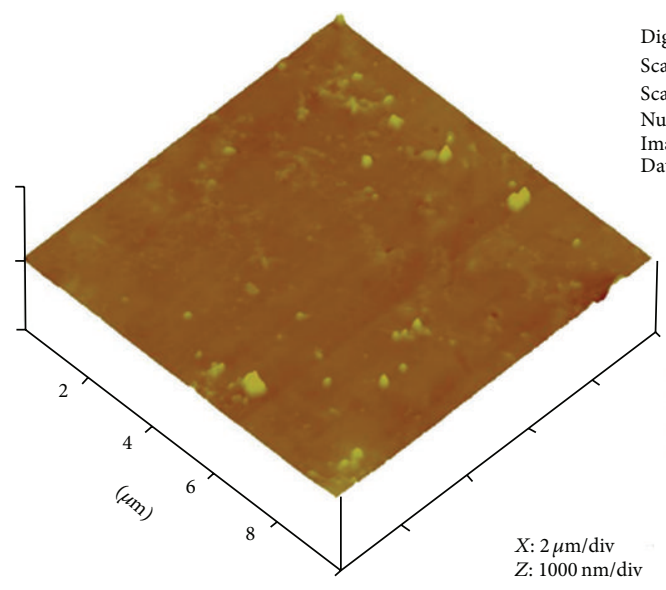

Pual-luv.001

Digital instruments nanoscope Scan size: $10 \mu \mathrm{m}$

Scan rate: $1.001 \mathrm{~Hz}$

Number of samples: 256

Image data: height

Data scale: $1 \mu \mathrm{m}$

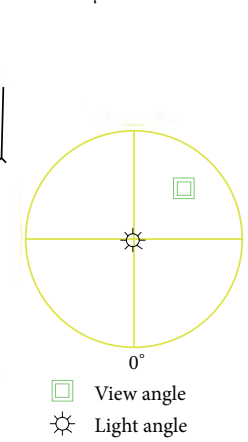

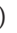

)

Height Angle Surface normal Clear calculator
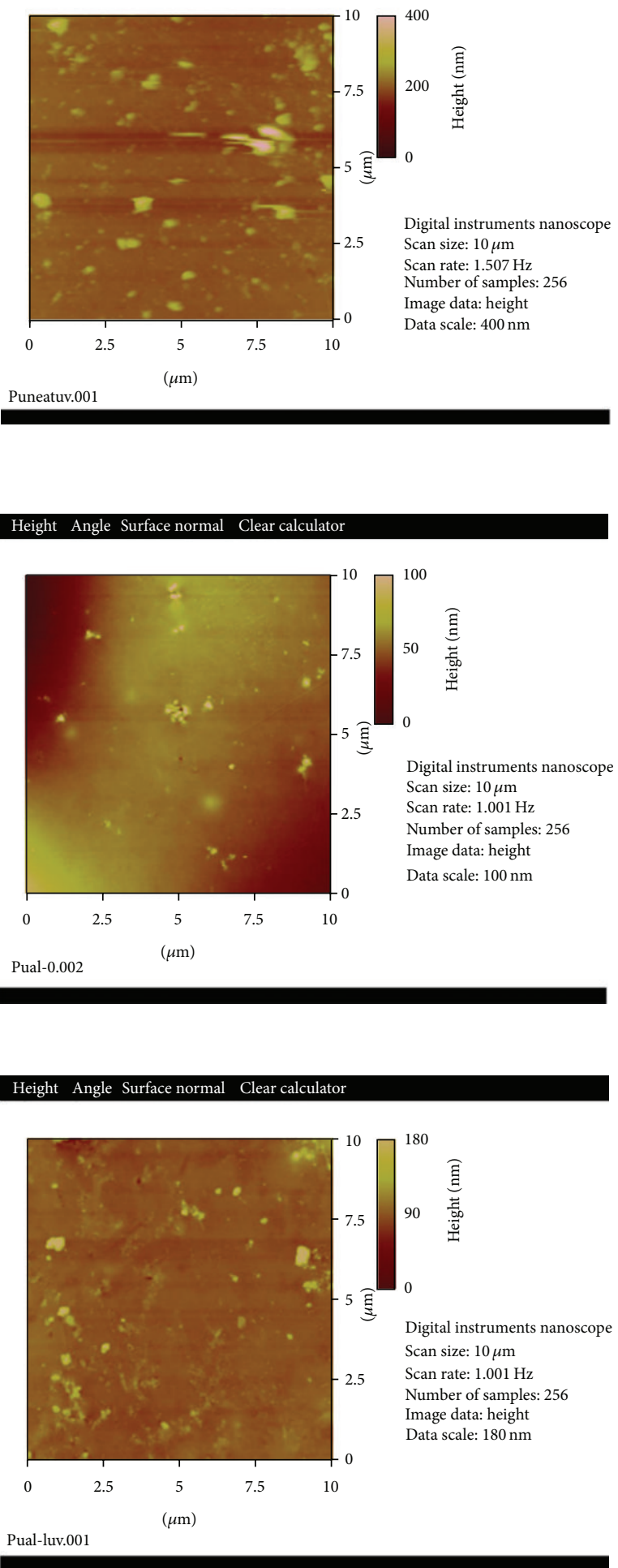

(c)

FIGURE 8: AFM topographic height images of UV-exposed coating surface at a scan size of $10 \mu \mathrm{m} \times 10 \mu \mathrm{m}$ : (a) neat WPUD, (b) WPUD + 0.1\% nanoalumina, and (c) WPUD + 1.0\% nanoalumina. 


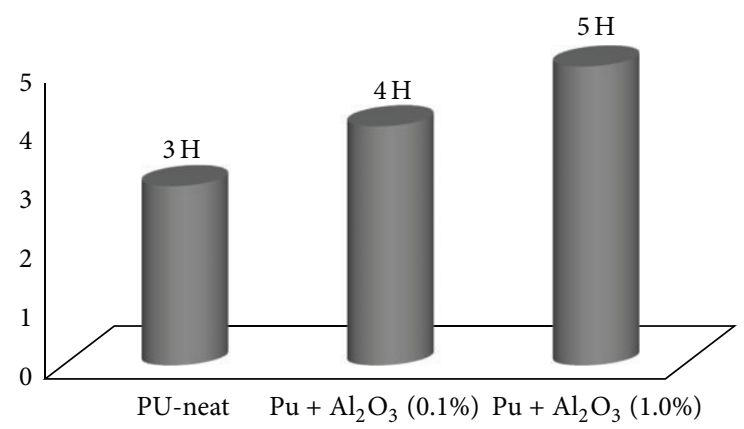

Pencil hardness $(H)$

FIgURE 9: Pencil hardness test.

compared to the coating modified with lower concentration of nanoalumina. The improvement of UV resistance of the modified coating can be attributed to the fact that nanoalumina has a wide band gap $(3.37 \mathrm{eV})$ and large excitation binding energy of $60 \mathrm{meV}$; therefore, it can absorb light that matches or exceeds their band gap energy and which lies in the UV range of the solar spectrum [28, 29]. Thus, a welldispersed nanoalumina particles attenuate UV radiations and protect the polymer matrix from degradation. Figure 8 shows the AFM topographic height image of UV-exposed samples. For Neat WPUD coating the surface appears to be more heterogeneous with increased roughness, indicating surface degradation (Figure 8(a)). Coating with $0.1 \%$ nanoalumina shows effective improvement in UV blocking properties (Figure $8(\mathrm{~b})$ ). It can be attributed that the small surface area per unit mass and volume increases the effectiveness of the blocking UV radiation and prevents photodegradation of base polymer matrix. Also, nanoalumina due to its ceramic nature is inherently stable [30] and at this dimension possesses lower photochemical activity [31] thereby providing good UV blocking property to the coating system without interacting with the UV radiation. However, the performance of nanoalumina at higher loading level is not satisfactory, as presence of pinholes and cracks is clearly seen (Figure 8(c)) due to formation of agglomeration in the coating matrix.

3.2.2. AFM Surface Roughness Analysis. Table 1 represents surface roughness values for neat WPUD and nano- $\mathrm{Al}_{2} \mathrm{O}_{3}$ modified WPUD coating systems, before and after exposure to the test environment. After exposure to various test environments, it was found that the surface roughness of neat sample is higher due to breakdown of polymer matrix as compared to the surface roughness of nano$\mathrm{Al}_{2} \mathrm{O}_{3}$-modified coating. This suggests the improvement in the properties of the coating after modification. However, the surface roughness of coating modified with $0.1 \%$ nano$\mathrm{Al}_{2} \mathrm{O}_{3}$ was relatively less than the coating modified with $1.0 \%$ nano- $\mathrm{Al}_{2} \mathrm{O}_{3}$, suggesting that for a higher loading level of nanoparticles the resin available is not sufficient to fill all interpigmentary interstices leading to porous film with inferior corrosion resistance.

\subsection{Mechanical Characterization}

3.3.1. Pencil Hardness. The surface hardness is an important property of coatings, because a harder surface resists scratch and abrasive forces better. Pencil hardness test was carried out for neat WPUD and nanoalumina $(0.1 \%$ by wt and $1.0 \%$ by wt) modified with WPUD-coated samples (Figure 9). Pencil hardness for the neat-WPUD-coated sample was found to be $3 \mathrm{H}$. With addition of nanoalumina particles, the hardness of the coating was enhanced, and the grade is $5 \mathrm{H}$ at the higher loading level $(1.0 \%)$ and $4 \mathrm{H}$ at lower loading level $(0.1 \%)$.

3.3.2. Nanoscratch Testing. The AFM-scanned pictures for the scratched coatings are shown in Figure 10. A distinct difference in the scratch morphology is observed on neat-WPUD (Figure 10(a)) and nanoalumina modified with WPUD coating (Figures 10(b) and 10(c)). A straight, wider, and completely clear scratch was obtained for the neatWPUD coating (Figure 10(a)). On the other hand, the profile of the scratch was not straight and uniform for the nanoalumina modified coating (Figures 10(b) and 10(c)), suggesting the resistance towards scratch damage after modification. The homogeneous distribution of nanoparticles toughens the coating system by hindering the mobility of macromolecular chains at the interface around the nanoparticles thereby improving the scratch resistance property [32, 33]. Also, the width of the scratch profile for neat-WPUD coating is narrow, whereas the width of the scratch profile for nanoalumina modified coatings is broad, suggesting that the lateral force required to create scratch to the nanoaluminamodified coating is higher as compared to the neat-WPUD coating. Thus, addition of nanoalumina (hardness of 9 Mohs) particles inhibits the crack formation and propagation during the scratch process. It is also apparent that the addition of nanoalumina in higher concentrations decreases the hardness because of nanoparticle aggregation [34]. This may be the probable reason for relatively less resistance offered by the coating modified with $1.0 \%$ nanoalumina as compared to coating modified with $0.1 \%$ nanoalumina.

\section{Conclusions}

In the present study, two different concentrations of nanoalumina particles $(0.1 \mathrm{wt} \%$ and $1.0 \mathrm{wt} \%)$ were employed to prepare nanocomposite polyurethane coatings. Although, the neat-WPUD coating acts as a barrier against corrosive environment, the protection seems to be reduced due to the diffusion of corrosive electrolyte through the coating film after long-term exposure to the corrosive environment. However, after modification with nanoalumina the coatings showed delay in corrosion process. The increase in the induction time of coating degradation may be attributed as a result of uniform distribution of nanoparticles which restricts the diffusion of the corrosive electrolyte through the coating film acting as an effective barrier. It was observed that UV degradation of the neat WPUD was also reduced after modification with nanoalumina, indicating improvement in UV resistance property. This may be attributed to the fact that at nanoscale the particles themselves effectively absorb 


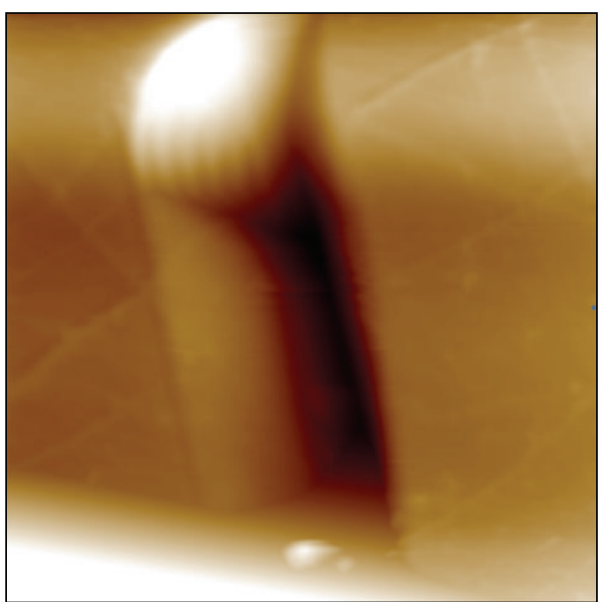

(a)

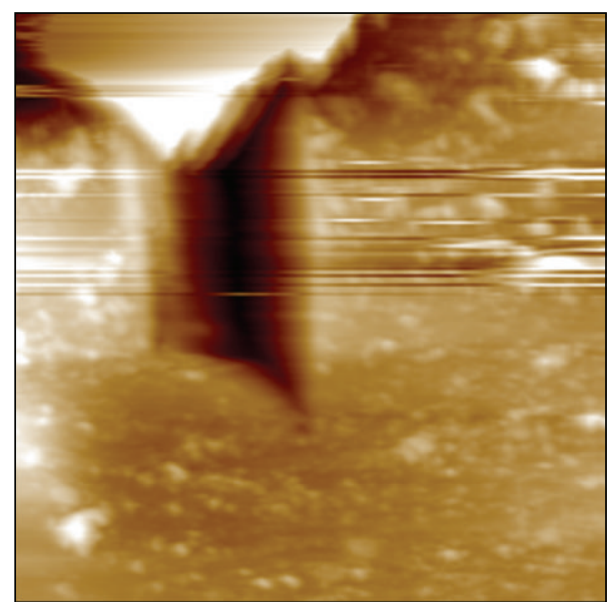

(b)

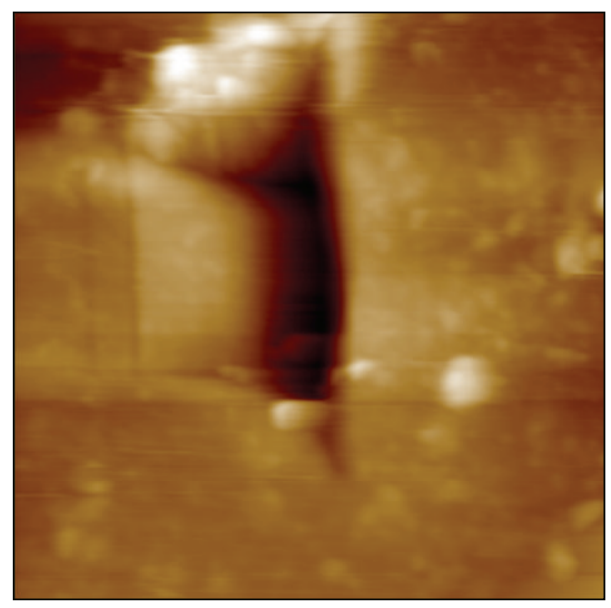

(c)

FIGURE 10: AFM scan pictures of scratched films of (a) neat WPUD, (b) WPUD + 0.1\% nanoalumina, and (c) WPUD + $1.0 \%$ nanoalumina.

TABLE 1: AFM Surface roughness values (nm) measured for coatings exposed to salt spray, humidity, and UV weathering.

\begin{tabular}{|c|c|c|c|}
\hline Test & Neat WPUD & WPUD + 0.1\% Nanoalumina & WPUD + $1.0 \%$ Nanoalumina \\
\hline Salt spray & $128.66 \mathrm{~nm}$ & $18.64 \mathrm{~nm}$ & $47.72 \mathrm{~nm}$ \\
\hline Humidity & $132.71 \mathrm{~nm}$ & $6.79 \mathrm{~nm}$ & $17.93 \mathrm{~nm}$ \\
\hline UV weathering & $20.54 \mathrm{~nm}$ & $10.70 \mathrm{~nm}$ & $13.94 \mathrm{~nm}$ \\
\hline
\end{tabular}

rather than scatter the UV radiation providing UV protection to the polymer. A considerable improvement in the electrochemical, UV weathering, and mechanical (hardness and scratch) properties of the WPUD coating modified with $0.1 \mathrm{wt} \%$ nanoalumina particles was observed. However, optimizing the concentration and improving the dispersion of nanoalumina in the polymer matrix can further improve the performance properties of the WPUD.

\section{References}

[1] B. K. Kim, “Aqueous polyurethane dispersions," Colloid Polymer Science, vol. 274, pp. 599-611, 1996.
[2] M. G. Lu, J. Y. Lee, M. J. Shim, and S. W. Kim, "Synthesis and properties of anionic aqueous polyurethane dispersions," Journal of Applied Polymer Science, vol. 86, no. 14, pp. 34613465, 2002.

[3] K. L. Noble, "Waterborne polyurethanes," Progress in Organic Coatings, vol. 32, no. 1-4, pp. 131-136, 1997.

[4] R. G. Coogan, "Post-crosslinking of water-borne urethanes," Progress in Organic Coatings, vol. 32, no. 1-4, pp. 51-63, 1997.

[5] H. S. Bender, "Overview of polyurethane dispersion chemistry," in FSCT Coating Fundamental: Waterborne Coating Technology, pp. 41-47, 2004.

[6] S. Heberer, R. Maier, R. Mertsch, G. Michael, and M. Pridohl, Novel UV Protection Coatings Based on Nano-ZnO Particles, Smart Coatings III, Berlin, Germany, 2004. 
[7] S. Zhou, L. Wu, J. Sun, and W. Shen, "The change of the properties of acrylic-based polyurethane via addition of nanosilica," Progress in Organic Coatings, vol. 45, no. 1, pp. 33-42, 2002.

[8] J. Zheng, R. Ozisik, and R. W. Siegel, "Disruption of selfassembly and altered mechanical behavior in polyurethane/zinc oxide nanocomposites," Polymer, vol. 46, no. 24, pp. 1087310882, 2005.

[9] L. H. Yang, F. C. Liu, and E. H. Han, "Effects of P/B on the properties of anticorrosive coatings with different particle size," Progress in Organic Coatings, vol. 53, no. 2, pp. 91-98, 2005.

[10] J. González-Irun Rodrigúez, P. Carreira, A. García et al., "Nanofiller effect on the glass transition of a polyurethane," Journal of Thermal Analysis and Calorimetry, vol. 87, no. 1, pp. 45-47, 2004.

[11] S. X. Zhou, L. M. Wu, J. Sun, and W. D. Shen, "Effect of nanosilica on the properties of polyester-based polyurethane," Journal of Applied Polymer Science, vol. 88, no. 1, pp. 189-193, 2003.

[12] M. M. Jalili, S. Moradian, H. Dastmalchian, and A. Karbasi, "Investigating the variations in properties of 2-pack polyurethane clear coat through separate incorporation of hydrophilic and hydrophobic nano-silica," Progress in Organic Coatings, vol. 59, no. 1, pp. 81-87, 2007.

[13] Z. S. Petrović, Y. J. Cho, I. Javni et al., "Effect of silica nanoparticles on morphology of segmented polyurethanes," Polymer, vol. 45, no. 12, pp. 4285-4295, 2004.

[14] R. Fernando, "Nanomateriál technology applications in coatings," JCT CoatingsTech, vol. 1, no. 5, pp. 32-38, 2004.

[15] R. H. Cayton and T. Swaitowski, The Impact of Nano-Materials on Coating Technologies, vol. 2, NSTI-Nanotech, 2005.

[16] N. S. Allen, M. Edge, A. Ortega et al., "Degradation and stabilisation of polymers and coatings: nano versus pigmentary titania particles," Polymer Degradation and Stability, vol. 85, no. 3, pp. 927-946, 2004.

[17] A. Ammala, A. J. Hill, P. Meakin, S. J. Pas, and T. W. Turney, "Degradation studies of polyolefins incorporating transparent nanoparticulate zinc oxide UV stabilizers," Journal of Nanoparticle Research, vol. 4, no. 1-2, pp. 167-174, 2002.

[18] R. H. Cayton and R. W. Brotzman Jr., "Nanocomposite coatingsapplications and properties," in Materials Research Society Symposium Proceedings, vol. 703, 2002.

[19] L. J. Brickweg, B. R. Floryancic, E. D. Sapper, and R. H. Fernando, "Shear-induced 1-D alignment of alumina nanoparticles in coatings," Journal of Coating Technology and Research, vol. 4, no. 1, pp. 107-110, 2007.

[20] S. K. Dhoke, T. J. Mangal Sinha, and A. S. Khanna, "Effect of nano- $\mathrm{Al}_{2} \mathrm{O}_{3}$ particles on the corrosion behavior of alkyd based waterborne coatings," Journal of Coatings Technology Research, vol. 6, no. 3, pp. 353-368, 2009.

[21] S. K. Dhoke and A. S. Khanna, "Electrochemical impedance spectroscopy (EIS) study of nano-alumina modified alkyd based waterborne coatings," Progress in Organic Coatings, vol. 74, pp. 92-99, 2012.

[22] Q. Wang, M. Yang, and Y. Chen, "Effects of nanosized iron oxide with different morphology on nanomechanical properties of nanocomposite coating," Key Engineering Materials, vol. 336338, pp. 2218-2220, 2007.

[23] A. S. Hamdy, "Advanced nano-particles anti-corrosion ceria based sol gel coatings for aluminum alloys," Materials Letters, vol. 60 , no. 21-22, pp. 2633-2637, 2006.
[24] S. Kozhukharov, G. Tsaneva, V. Kozhukhuarov et al., "Corrosion protection properties of composite hybrid coatings with involved nano-particles of zirconia and ceria," Journal of the University of Chemical Technology and Metallurgy, vol. 43, no. 1, pp. 73-80, 2008.

[25] D. R. Baer, P. E. Burrows, and A. A. El-Azab, "Enhancing coating functionality using nanoscience and nanotechnology," Progress in Organic Coatings, vol. 47, no. 3-4, pp. 342-356, 2002.

[26] A. Kalendová, "Effects of particle sizes and shapes of zinc metal on the properties of anticorrosive coatings," Progress in Organic Coatings, vol. 46, no. 4, pp. 324-332, 2003.

[27] H. Shi, F. Liu, E. Han, and Y. Wei, "Effects of nano pigments on the corrosion resistance of alkyd coating," Journal of Materials Science and Technology, vol. 23, no. 4, pp. 551-558, 2007.

[28] H. F. Lu, B. Fei, J. H. Xin, R. Wang, and L. Li, "Fabrication of UV-blocking nanohybrid coating via miniemulsion polymerization," Journal of Colloid and Interface Science, vol. 300, no. 1, pp. 111-116, 2006.

[29] S. M. Al-Hilli and M. Willander, "Optical properties of zinc oxide nano-particles embedded in dielectric medium for UV region: numerical simulation," Journal of Nanoparticle Research, vol. 8, no. 1, pp. 79-97, 2006.

[30] B. Pacaud, J. N. Bousseau, and J. Lemaire, "Nano-titania as UV blockers in stains," European Coatings Journal, no. 11, pp. 842848, 1998.

[31] S. Heberer, R. Maier, R. Mertsch, G. Michael, and M. Pridohl, "Novel UV protection coatings based on Nano-ZnO particles," in Proceedings of the European Coatings Conference: Smart Coatings III, Berlin, Germany, June 2004.

[32] S. K. Dhoke, R. Bhandari, and A. S. Khanna, "Effect of nano$\mathrm{ZnO}$ addition on the silicone-modified alkyd-based waterborne coatings on its mechanical and heat-resistance properties," Progress in Organic Coatings, vol. 64, no. 1, pp. 39-46, 2009.

[33] P. Kardar, M. Ebrahimi, and S. Bastani, "Study the effect of nano-alumina particles on physical-mechanical properties of UV cured epoxy acrylate via nano-indentation," Progress in Organic Coatings, vol. 62, no. 3, pp. 321-325, 2008.

[34] C. Sow, B. Riedl, and P. Blanchet, "UV-waterborne polyurethane-acrylate nanocomposite coatings containing alumina and silica nanoparticles for wood: Mechanical, optical, and thermal properties assessment," Journal of Coatings Technology Research, vol. 8, no. 2, pp. 211-221, 2011. 

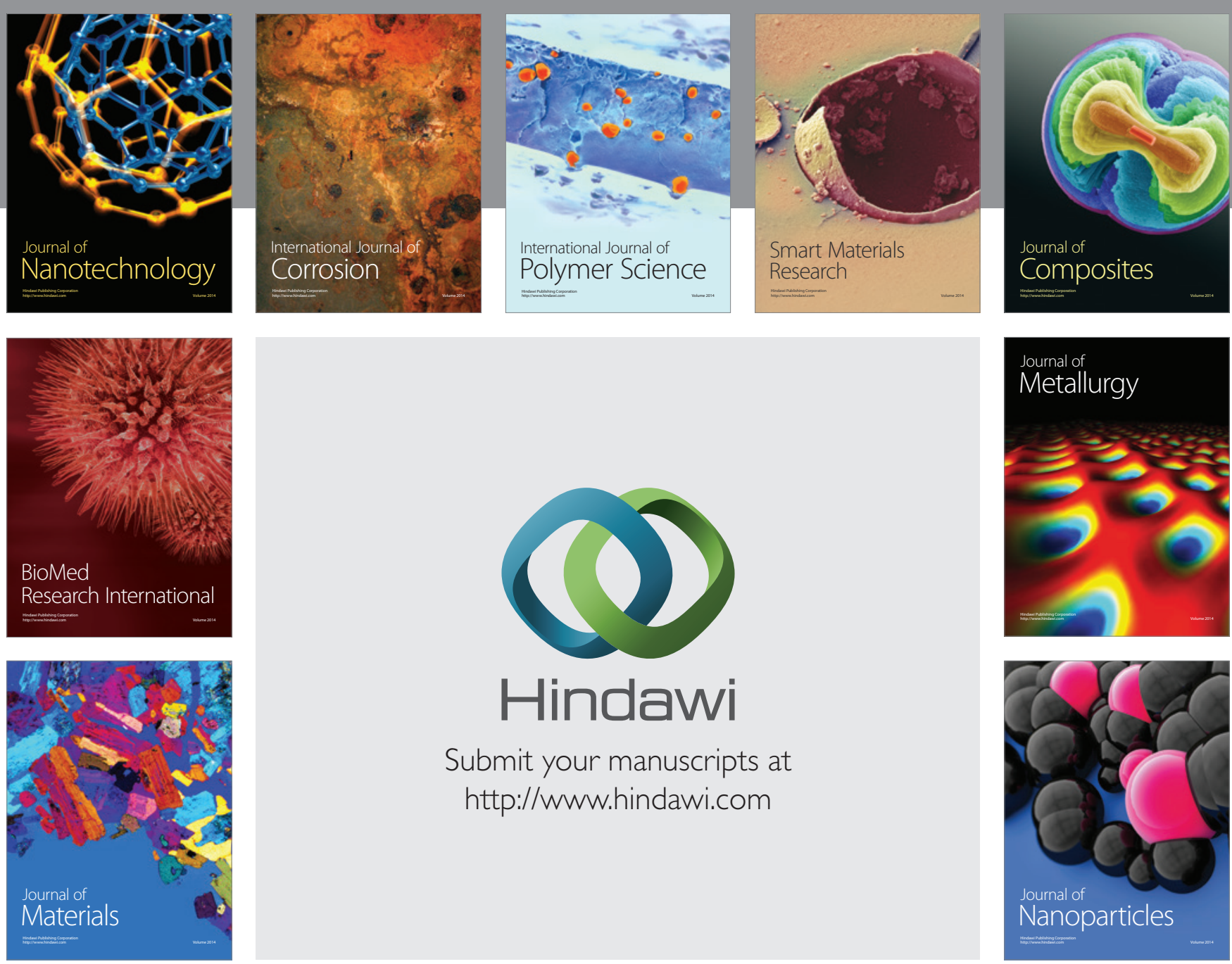

Submit your manuscripts at http://www.hindawi.com
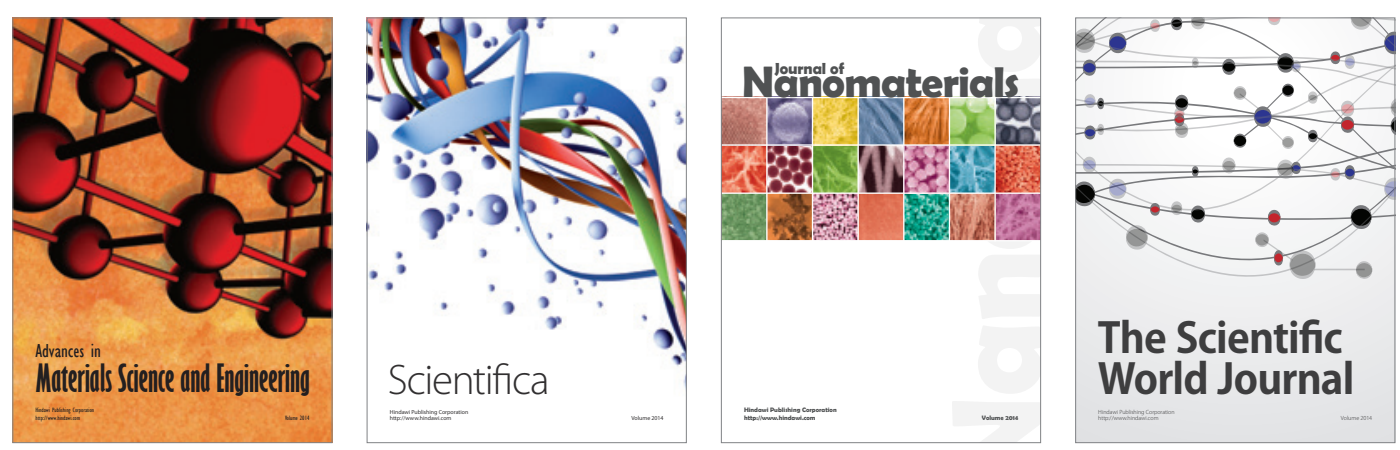

\section{The Scientific World Journal}
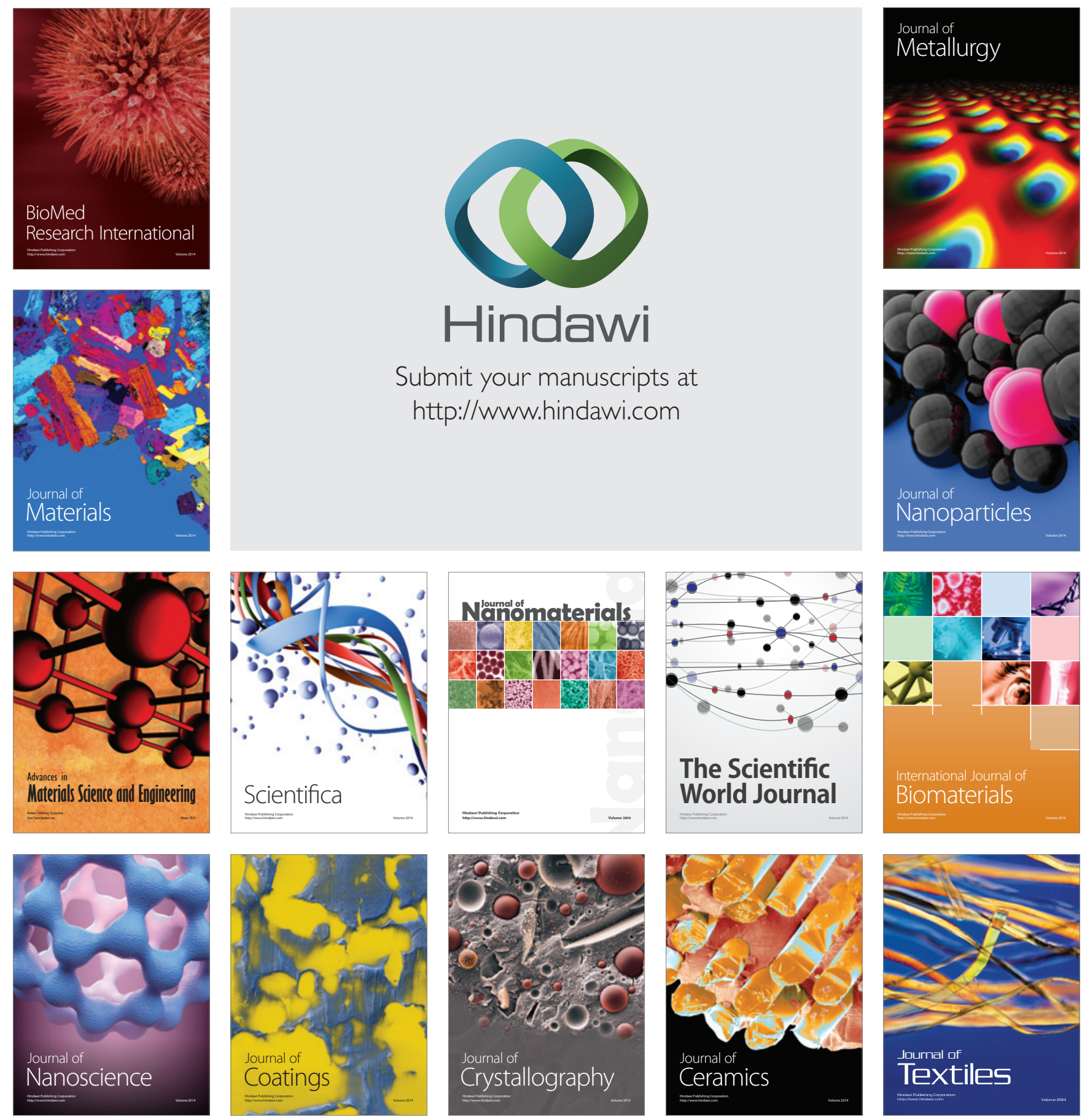